\title{
An experimental analysis of species sorting and mass effects in freshwater bacterioplankton
}

\author{
CAROLINE SOUFFREAU, BERT PECCEU, CARLA DENIS, KOEN RUMMENS AND LUC DE MEESTER \\ Laboratory of Aquatic Ecology, Evolution \& Conservation, KU Leuven, Leuven, Belgium
}

\section{SUMMARY}

1. While metacommunities of bacterioplankton are generally considered to be structured primarily by local environmental conditions (through species sorting), additional ecological processes such as dispersal limitation, neutral dynamics or mass effects can influence community structure. Under the mass effects paradigm, continuous or large influxes of organisms, not self-maintaining in the target environment, affect community structure.

2. We used communities of freshwater bacterioplankton to quantify the outcome of mass effects and species sorting in a laboratory experiment in which we exchanged cells between two communities from contrasting ponds (eutrophic and mesotrophic) at a rate of 0.025, 0.25, 2.5 and $12.5 \%$ of the cells present per day.

3. When cells were exchanged only once on day 1 of the experiment, the reciprocally exchanged communities in all dispersal treatments remained as divergent, after 20 days, as the unexchanged control communities, reflecting strong species sorting and no strong influences of dispersal limitation and neutral dynamics on the observed bacterioplankton.

4. Under daily cell exchange, however, community similarity between the reciprocally exchanged communities increased significantly with increasing dispersal rate, indicating an increasing influence of mass effects relative to species sorting. The responses differed at the level of community composition and ecosystem processes, and depended on pond identity. At the community level, a daily exchange of $2.5 \%$ was necessary to increase community similarity compared with the unexchanged controls, while at the ecosystem process level (Biolog GN2 metabolic profiles), a daily exchange rate of $0.25 \%$ was sufficient.

5. Mass effects can evidently overcome species sorting in freshwater bacterioplankton, but only under relatively high dispersal rates that are unlikely to occur in nature among habitats without a direct hydrological connection. Mass effects in the freshwater bacterioplankton acted differently at the community composition and ecosystem process level.

Keywords: ecosystem processes, freshwater bacterioplankton, metacommunity ecology, microbial communities

\section{Introduction}

Metacommunities are defined as a set of local communities linked by dispersal of potentially interacting species (Leibold et al., 2004; Holyoak, Leibold \& Holt, 2005). The ecological processes shaping local community structure can be diverse and mutually non-exclusive and include processes at the local and regional scale (Leibold et al., 2004). Quantifying the importance of local and regional processes in shaping metacommunity structure, and determining which processes are at work under which conditions, is crucial to understand the observed patterns in community structure in natural systems and to predict community shifts in changing environments. This is also a particularly useful exercise for the bacterioplankton, because of the fundamental importance of bacteria in ecosystems. Field studies have shown that metacommunities of freshwater bacterioplankton are

Correspondence: Caroline Souffreau, Laboratory of Aquatic Ecology, Evolution \& Conservation, KU Leuven, Charles Deberiotstraat 32 , 3000 Leuven, Belgium. E-mail: caroline.souffreau@bio.kuleuven.be 
primarily structured by the local abiotic and biotic conditions (e.g. Beisner et al., 2006; Van Der Gucht et al., 2007; Logue \& Lindström, 2010; De Bie et al., 2012; Langenheder et al., 2012), an ecological process that is termed species sorting. The species sorting paradigm requires that the presence of species in a habitat is not limited by dispersal but only by the local conditions; however, dispersal should not be so high that it influences species composition by source-sink dynamics. As a result, dispersal does not directly influence community composition but only facilitates its responses to local environmental conditions (Leibold, 1998; Chase \& Leibold, 2002; Leibold et al., 2004). The observed importance of local environmental conditions for the bacterioplankton has been ascribed to high dispersal rates combined with rapid local dynamics of bacteria, due to their high population growth rates (Van Der Gucht et al., 2007). However, it has also been argued that the emphasis on species sorting could be an artefact because it is the mechanism that is easiest to measure, detect and interpret (Lindström \& Langenheder, 2012; Östman et al., 2012).

The dominant signal of species sorting in most analyses of the freshwater bacterioplankton suggests that regional processes, which emphasise dispersal dynamics and include dispersal limitation, neutral processes and mass effects (Leibold et al., 2004), are less important in structuring these communities. Nevertheless, regional processes have been reported to influence bacterial community composition in the field (reviewed in Hanson et al., 2012; Lindström \& Langenheder, 2012). Although in practice it is often difficult to interpret unequivocally patterns of community structure as the result of dispersal limitation, dispersal limitation of bacteria has been shown at larger spatial scales (e.g. Schauer et al., 2010) and in specialised habitats (e.g. Whitaker, Grogan \& Taylor, 2003). Further, several studies have reported that the distribution of abundance in bacterial communities is consistent with the neutral model (Sloan et al., 2006; Woodcock et al., 2007; Drakare \& Liess, 2010; Östman et al., 2010). The neutral model assumes that community assembly is stochastic and regulated by random dispersal, colonisation, specialisation and extinction events among functionally equivalent species (Hubbell, 2006). However, these studies on abundance distribution suffer from the problem that observed similarities in patterns can be generated through other mechanisms. Indeed, several studies have suggested that distribution patterns reflect a combination of neutral processes and species sorting (Ofiteru et al., 2010; Langenheder \& Székely, 2011).
Under the mass effects paradigm, community structure is affected by the continuous or massive immigration of organisms that are not self-maintaining in the target environment (Shmida \& Whittaker, 1981; Shmida \& Ellner, 1984; Shmida \& Wilson, 1985). In this case, the process of species sorting, and thus selection by the local environment, is not sufficient to overcome the large or continuous influx of maladapted taxa, resulting in variations in community structure that cannot be explained by the measured local environmental parameters. Theoretical studies on mass effects and source-sink dynamics predict strong effects on species abundances (Levin, 1974; Shmida \& Ellner, 1984; Holt, 1985a; Pulliam, 1988, 2000; Mouquet \& Loreau, 2002; Holt, Barfield \& Gonzalez, 2003) and species interactions (Holt, 1985b; Danielson, 1991), both resulting in effects on community structure and dynamics (Holt et al., 2003). Because mass effects can have profound effects on local and regional diversity (Wilson \& Shmida, 1984; Forbes \& Chase, 2002; Kneitel \& Miller, 2003; Mouquet \& Loreau, 2003), productivity (Matthiessen \& Hillebrand, 2006; Venail et al., 2008, 2010) and ecosystem processes (Holt \& Loreau, 2001; Gonzalez \& Chaneton, 2002), it is important to assess the occurrence and importance of this process. In the laboratory, coexistence due to mass effects has been shown experimentally for protozoan and rotifer assemblages living in the water-filled leaves of the pitcher plant Sarracenia purpurea (Kneitel \& Miller, 2003), in a laboratory-scale food web consisting of bacteria and four protist species (Holyoak, 2000) and in experiments with bacteria (Venail et al., 2010) and algae (Codeço \& Grover, 2001).

In the freshwater bacterioplankton, the available field and experimental data on mass effects are inconsistent. Several studies have suggested that their community composition in lakes can be influenced by bacteria arriving (Crump et al., 2003; Masin et al., 2003; Lindström \& Bergström, 2004), and signatures of mass effects have been detected in freshwater systems with short hydrological residence time (Lindström et al., 2006; Crump et al., 2007; Nelson, Sadro \& Melack, 2009; Shabarova, Widmer \& Pernthaler, 2013). However, in these studies, environmental conditions in the habitats under study converged with those in the source system, because of the high influx rate, making the distinction between species sorting and mass effects difficult. When the similarity in conditions (because of the influx of water) is decoupled from the cell import rate, mass effects become less important compared with species sorting in explaining bacterial community composition (Lindström et al., 2010; Logue \& Lindström, 2010). Moreover, it has been 
suggested that species sorting can be more efficient in lakes with high nutrient concentrations than in less fertile lakes, because of the higher population growth rates in the former (Van Der Gucht et al., 2007), a hypothesis that was confirmed in an experimental study on mass effects (Lindström \& Östman, 2011). The emerging picture is that mass effects may occur in the bacterioplankton, but that their relative importance is unclear, as is their effect on ecosystem processes. At this stage, generalisations on the occurrence and consequences of mass effects in microbial communities are still hard to make. In particular, there is a need for data on how high dispersal rates among habitats must be for mass effects to be detectable.

Previous experiments (Jones \& McMahon, 2009; Lindström \& Östman, 2011) and a field survey (Logue \& Lindström, 2010) have suggested that dispersal rate needs to be very high to overwhelm the local dynamics of species sorting in bacterial communities. Lindström \& Östman (2011) observed that in their experimental system, the greatest change in bacterial community composition and bacterial growth rate occurred when between 10 and $43 \%$ of the standing stock was replaced by bacteria from another system per day, but that the effect of dispersal on both community composition and ecosystem processes depended on the quality of the habitat into which the bacteria disperse. In this study, we assessed the influence of a single as well as repeated (daily) exchange of bacteria on community composition and ecosystem processes starting with complex bacterial communities isolated from natural systems. Both for the single and for daily exchange, we quantified the influence of a gradient in exchange rates of bacterioplankton cells $(0,0.025,0.25,2.5$ and $12.5 \%$ of the cells present) between two environmentally distinct natural pond waters. The two distinct media were expected to lead to divergent bacterial communities through species sorting. A single exchange might alleviate dispersal limitation and could thus result in a changed response to the environmental gradient compared with the control treatment without exchange. A repeated exchange may induce mass effects and thus lead to convergence in the composition of the bacterioplankton and ecosystem processes.

\section{Methods}

\section{Experimental set-up}

The experiment was conducted using water and bacteria from two environmentally contrasting ponds. One (Zoet Water, Oud-Heverlee, Belgium) is highly eutrophic, containing high concentrations of suspended material. The second pond (De Maten lake 13, Genk, Belgium) is mesotrophic and contains humic acids (see Table 1 for physical and chemical characteristics of the two systems). Water was sampled the day before the start of the experiment and filtered through a $5-\mu \mathrm{m}$-mesh-size filter (Merck Millipore, Darmstadt, Germany, MCE) to exclude larger organisms. The experiment was conducted in sterile 50-mL centrifugation tubes (Greiner Bio-One, Frickenhausen, Germany) filled with $30 \mathrm{~mL}$ filtered water from one of the ponds with natural cell densities. The tubes were incubated for 20 days at $18{ }^{\circ} \mathrm{C}$ in the dark. Two sets of parallel manipulations were carried out. In one set, tubes were paired across ponds (i.e. the two tubes contained water from the different ponds), and bacterial cells were exchanged daily between tubes. A dispersal gradient was created by mutually exchanging $0.025,0.25,2.5$ or $12.5 \%$ of the bacterial cells between tubes daily. A control treatment without exchange was included. Each treatment consisted of five replicates, yielding five exchange rates $x$ two ponds $x$ five replicates $=50$ experimental units. In a second set of tubes, bacteria were exchanged between the ponds once only at the start of the experiment (day 1). This manipulation tested for dispersal limitation and neutral dynamics. As cells were exchanged only once, the total amount of cells transferred for each dispersal treatment was lower in the single exchange than in the daily exchange.

To exchange cells, $0.1,1,10$ and $50 \%$ of the water volume was centrifuged for $15 \mathrm{~min}$ at $1800 \mathrm{rcf}$, pelletising an estimated $0.025,0.25,2.5$ and $12.5 \%$ of the total number of cells present, respectively (because centrifugation is not $100 \%$ efficient, see below). The supernatant was put back in the original experimental unit, while the pellet was resuspended in $5 \mathrm{~mL}$ water of the target unit and vortexed during $30 \mathrm{~s}$ before transfer to the target

Table 1 Overview of some environmental parameters measured in situ on 23 October 2012 (Zoet Water) and 30 October 2012 (De Maten) at $10 \mathrm{~h}$ or on water samples collected at that moment, following the methods described in De Bie et al. (2012). Sneller depth is the deepest point under water (in $\mathrm{cm}$ ) at which a small $(7 \mathrm{~cm}$ diameter) Secchi disc, lowered in a grey PVC tube $(8 \mathrm{~cm}$ diameter) filled with lake water, can be seen

\begin{tabular}{lcc}
\hline Parameter & Zoet Water & De Maten \\
\hline Sneller depth $(\mathrm{cm})$ & 40.0 & 58.0 \\
$\mathrm{pH}$ & 7.30 & 7.39 \\
$\mathrm{O}_{2}$ content $\left(\mathrm{mg} \mathrm{L}^{-1}\right)$ & 3.73 & 8.64 \\
Conductivity $\left(\mu \mathrm{S} \mathrm{cm}^{-1}\right)$ & 755 & 322 \\
Chlorophyll a $\left(\mu \mathrm{g} \mathrm{L}^{-1}\right)$ & 82.45 & 156.00 \\
Dissolved organic carbon $\left(\mathrm{mg} \mathrm{L}^{-1}\right)$ & 48.95 & 21.6 \\
Total nitrogen $\left(\mathrm{mg} \mathrm{L}^{-1}\right)$ & 6.44 & 0.65 \\
\hline
\end{tabular}


tube. Transfer between tubes was performed after removing the cells to be transferred from each tube. To exclude a differential effect of centrifugation on the bacterial community in the different treatments, a total of $15 \mathrm{~mL}$ of water was centrifuged for all treatments, including the treatment with no exchange, but split up in the appropriate proportions (one part of the bacteria being exchanged, the other part being resuspended and put back in the original tube). This procedure was continued for 20 days, after which all experimental units were sampled.

Based on our centrifugation method (1800 rcf for $15 \mathrm{~min})$, not all cells present in the centrifuged water volume were pelletised and thus exchanged. To account for the difference between the centrifuged water volume $(0.1,1,10$ and 50\%) and the effective number of pelletised and exchanged cells, we quantified the densities of effectively exchanged cells for the two ponds in a separate test and extrapolated these results to the entire experiment. Using exactly the same protocol as during the experiment, $15 \mathrm{~mL}$ of water of Zoet Water and De Maten was centrifuged in triplicate, the supernatants discarded, and the pellets resuspended in their respective filter-sterilised medium. Supernatants and resuspended pellets were fixed with paraformaldehyde (4\% final concentration). Cell densities of the supernatants and pellets were determined by flow cytometry using an Attune ${ }^{\circledR}$ Acoustic Focussing Cytometer (Life Technologies, Gent, Belgium) equipped with a VL1 (450/40 $\mathrm{nm})$ BP filter under the excitation of a 405-nm laser. Fixed water samples were passed through a $11-\mu \mathrm{m}$ filter, stained with 4',6-diamidino-2phenylindole (DAPI; $10 \mu \mathrm{g} \mathrm{mL}^{-1}$ final concentration, $10 \mathrm{~min}$ incubation) and diluted 100-fold. Cells were captured with a collection rate of $25 \mu \mathrm{g} \mathrm{mL}^{-1}$, and a total of $100 \mu \mathrm{L}$ was analysed per sample. The average percentage of pelletised cells was calculated per medium type based on triplicate values and showed that $c$. $25 \%$ (De Maten: average $26.04 \pm 1.02 \%$ standard deviation; Zoet Water: average $25.73 \pm 1.38 \%$ standard deviation) of the cells present in the centrifuged water were pelletised. Although these tests were performed on communities taken at a different time from the experiment, centrifugation of both De Maten and Zoet Water resulted in a similar percentage of pelletised cells leading us to assume that a harvesting efficiency of $25 \%$ could be applied to our original experiment and that differences in the percentage of pelletised cells between the two communities were probably small. However, there is some uncertainty in this, and our results should be interpreted with caution.

\section{DNA-extraction and Terminal Restriction Fragment} Length Polymorphism (T-RFLP) analysis

The community composition of all experimental units was characterised using the genetic fingerprinting technique T-RFLP. After 20 days, $4 \mathrm{~mL}$ of water per replicate were centrifuged at $13400 \mathrm{rcf}$ for $15 \mathrm{~min}$. DNA was extracted from the pellet using the protocol for maximum yield of the UltraClean ${ }^{\mathrm{TM}}$ Soil DNA isolation kit (MoBio Laboratories Inc., Carlsbad, CA, U.S.A.). For T-RFLP fingerprinting, the extracted DNA was amplified using the bacterial universal primers 8-27F (5'-AGAGTTT GATCCTGGCTCAG-3'), which was 6-FAM labelled at the 5'-end, and 907-926R (5'-CCGTCAATTCCTTTTAG TTT-3') (Liu et al., 1997). The PCRs (total volume of $25 \mu \mathrm{L}$ ) contained $1 \mu \mathrm{L}$ template DNA, $0.4 \mu \mathrm{M}$ of each primer, $2 \mathrm{~mm} \mathrm{MgCl}_{2}, 2.5 \mu \mathrm{L} \mathrm{10 \times} \mathrm{PCR} \mathrm{buffer} \mathrm{(Eurogentec),}$ $200 \mathrm{~mm}$ of each dNTP and $0.25 \mu \mathrm{L}$ Silverstar Taqpolymerase (Eurogentec). Thermal cycling conditions were $94{ }^{\circ} \mathrm{C}$ for $2 \mathrm{~min}$, followed by 30 cycles of $94{ }^{\circ} \mathrm{C}$ for $1 \mathrm{~min}, 60{ }^{\circ} \mathrm{C}$ for $1 \mathrm{~min}, 72{ }^{\circ} \mathrm{C}$ for $1 \mathrm{~min}$ and final extension at $72{ }^{\circ} \mathrm{C}$ for $5 \mathrm{~min}$. PCR products were checked by UV-visualisation on $1.5 \%$ agarose gel after GelRed ${ }^{\mathrm{TM}}$ staining (Biotium, Hayward, CA, U.S.A.).

Excess of primers and salts was removed using NucleoFast purification based on microfiltration (MachereyNagel, Düren, Germany). PCR products were resuspended in $50 \mu \mathrm{L}$ MilliQ water, and DNA concentrations were measured with a ND-1000 NanoDrop spectrophotometer (NanoDrop Technologies, Wilmington, DE, U.S.A.). Digestion was performed by mixing $300 \mathrm{ng}$ of PCR product with $20 \mathrm{U}$ HhaI enzyme (Fermentas, Fisher Scientific, Pittsburgh, PA, U.S.A.) and incubating at $37{ }^{\circ} \mathrm{C}$ for $4 \mathrm{~h}$ (Smalla et al., 2007). We only used a single enzyme as several authors have shown no differences in phylotype richness and diversity when using more than one enzyme (Dunbar, Ticknor \& Kuske, 2001; Hartmann et al., 2005; Danovaro et al., 2006). Restriction digestions were stopped by freezing the samples at $-20{ }^{\circ} \mathrm{C}$. Excess of restriction enzyme and salts was removed with the illustra GFX PCR DNA and Gel Band Purification kit. DNA was eluted with $20 \mu \mathrm{L}$ MilliQ water and the concentration checked with NanoDrop, which was $c$. $10 \mathrm{ng} \mu \mathrm{L}^{-1}$. Capillary electrophoresis was performed with an ABI Prism 3130-Avant Genetic Analyser (Applied Biosystems, Life Technologies, Gent, Belgium) using POP 7 polymer. DNA was denaturised by mixing $2 \mu \mathrm{L}$ restriction product with $7.7 \mu \mathrm{L}$ formamide, and $0.3 \mu \mathrm{L}$ GeneScan ${ }^{\mathrm{TM}} 1200 \mathrm{Liz}^{\circledR}$ size standard (Applied Biosystems) was added. T-RFLP profiles were analysed using GeneMapper v.4.0 (Applied Biosystems) with a 
variation range of $1 \mathrm{bp}$ and minimal threshold of $50 \mathrm{flu}-$ orescence units. The profile alignment was manually corrected in excel based on the average size of each $\mathrm{T}-\mathrm{RF} \pm 1 \mathrm{bp}$ : T-RFs overlapping in average size $\pm 1 \mathrm{bp}$ were combined into a single T-RF, except if both original T-RFs were present in one or more of the replicates. Relative peak height was used as proxy for relative abundance.

\section{Community-level Biolog metabolic profiling}

Bacterial ecosystem processes in terms of metabolic potential were determined after 20 days using Biolog GN2 Microplate $^{\mathrm{TM}}$ (Biolog Inc., Hayward, CA, U.S.A.) containing 95 individual metabolisable molecules and 1 control well. Metabolisation of the molecules by the bacterial community triggers the reduction of a tetrazolium dye in the well, and this colour change is measured spectrophotometrically at $590 \mathrm{~nm}$. For three replicates per experimental treatment, $150 \mu \mathrm{L}$ water sample containing the bacterial community was brought directly into the wells (Garland \& Mills, 1991). The plates were incubated at $25{ }^{\circ} \mathrm{C}$ in the dark, and optical densities (ODs) were measured after 5 days. ODs of the metabolisable source-containing wells were corrected by subtraction of the control well OD and divided by the average well colour development (AWCD, average OD of the 95 source-containing wells after correction against the control well) (Preston-Mafham, Boddy \& Randerson, 2002). Negative ODs were replaced by zero values. Results based on a 3 day incubation yielded the same patterns as the 5 day incubation.

\section{Statistical analyses}

Statistical analyses were performed separately for the two individual experiments (daily and single exchange). For bacterial community analyses, only T-RFs with relative abundances higher than $0.2 \%$ of the total data set and present in more than one sample were included. Variation in bacterial community structure (Hellingertransformed presence-absence and relative abundance data) and in Biolog OD responses (log-transformed) over the five exchange treatments were visualised by principal component analysis (PCA) using the function rda from the R-package vegan (Oksanen et al., 2013). Additionally, non-metric multidimensional scaling (NMDS) was used to visualise variation in community structure using the function metaMDS of the R-package vegan (Oksanen et al., 2013) on Bray-Curtis similarities, starting from $k=5$ and using the best result as the new start- ing point until $k=2$. NMDS plots were compared using the function procrustes and, when reaching a stable configuration, the plot with the lowest stress value was selected. To assess formally the effect of exchange rates, water type and the interaction between exchange rates and water type on the community structure or processes, redundancy analysis (RDA) followed by a permutation test (10 000 permutations) was performed using the functions rda and anova.cca of the R-package vegan, while perMANOVA was performed on BrayCurtis community similarity data using the function adonis (10 000 permutations) of the same R-package.

To quantify the differentiation between the mutually exchanged replicates, Bray-Curtis similarities in community composition (presence-absence and relative abundance data) and in Biolog OD responses were calculated between the mutually exchanged replicates using the function bcdist in the R-package ecodist (Oksanen et al., 2013). To test for a correlation between exchange rate and Bray-Curtis community similarity of the mutually exchanged units, we performed Spearman's rank correlations using STATISTICA 64 version 10 (StatSoft, Inc., Tulsa, OK, U.S.A.). Significant differences in these BrayCurtis similarities among exchange rates were assessed by one-way ANOVA followed by a Tukey HSD post hoc test in STATISTICA 64 version 10 (StatSoft, Inc.). Significant differences in community composition or Biolog OD responses within the mutually exchanged groups were assessed by manual pairwise perMANOVA, as described above. To quantify the divergence in community structure or ecosystem processes of the exchanged replicates from the control treatment (or from the $12.5 \%$ exchange treatment) within each pond, RDA and perMANOVA between the control treatment (or 12.5\% exchange treatment) and each other exchange treatments were performed using the R-package vegan as described above. Before performing one- or two-way ANOVA, the homogeneity and normality of the variances of the data were tested using the Levene's test and Shapiro-Wilk test, respectively.

\section{Results}

\section{Single exchange}

When exchanging cells only at the start of the experiment, to test for species sorting and to control for dispersal limitation and neutral dynamics, the mutually exchanged communities did not converge with increasing dispersal rate, based on a PCA [Fig. 1; relative abundance data (RA)]. When based on presence-absence 

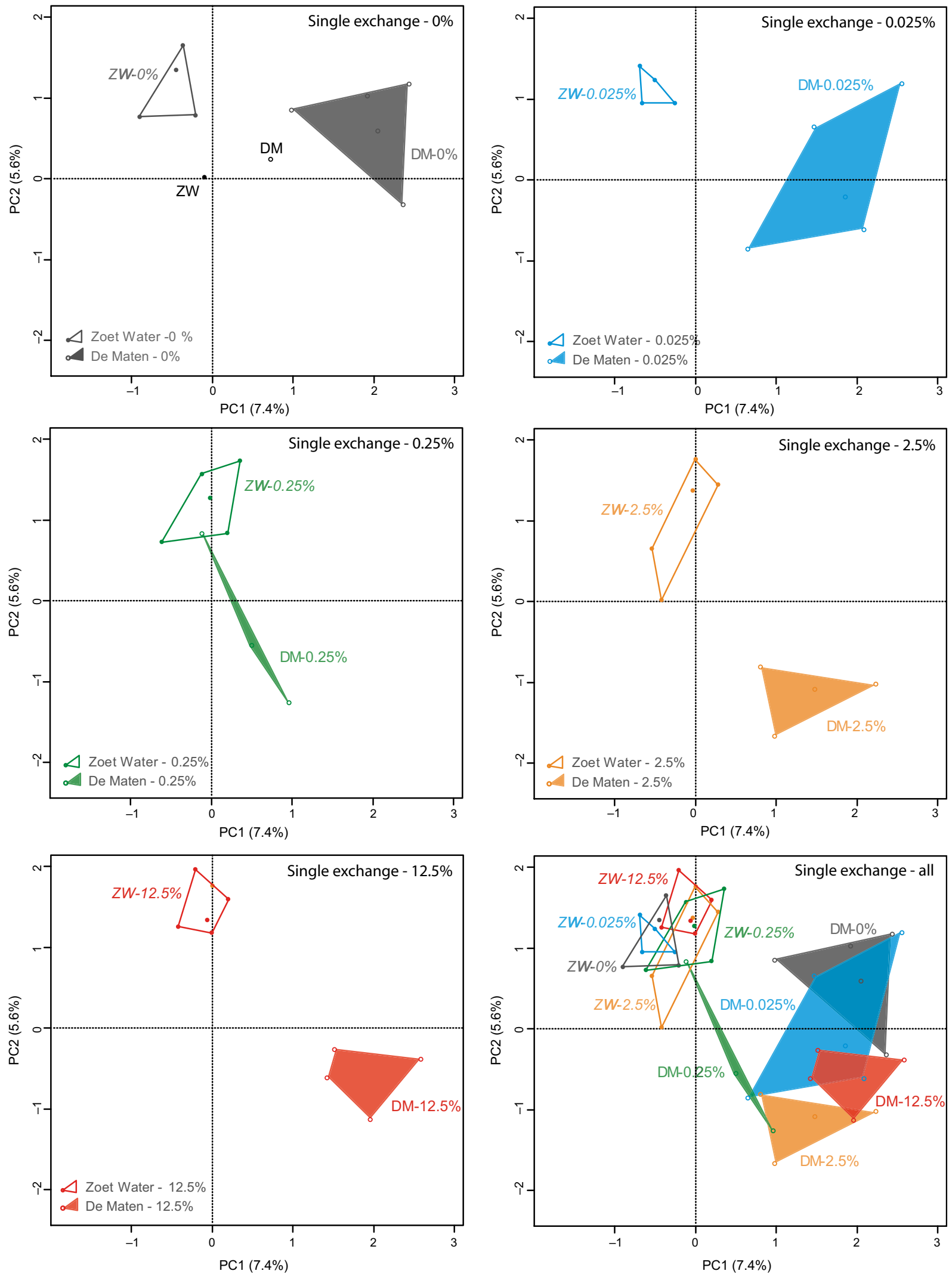

Fig. 1 PCA plots of the variation in bacterial community composition (relative abundance data) at different mutual exchange rates (0, 0.025 , $0.25,2.5$ and $12.5 \%$ of the cells present) plotted per exchange rate under one single exchange at the start of the experiment. DM = De Maten; $\mathrm{ZW}=$ Zoet Water. 
(PA) data, Bray-Curtis similarities in community composition calculated between the exchanged units remained equally dissimilar over the different exchange rates compared with the unexchanged control treatment (one-way ANOVA: $P>0.05$ ) (Fig. 2a, left panel) and even decreased significantly at $0.25 \%$ exchange compared with the control when based on relative abundance (RA) data (one-way ANOVA: $P=0.0021$; Tukey HSD: $P=0.025)$ (Fig. $2 \mathrm{~b}$, left panel). All mutually exchanged communities differed significantly between ponds at the
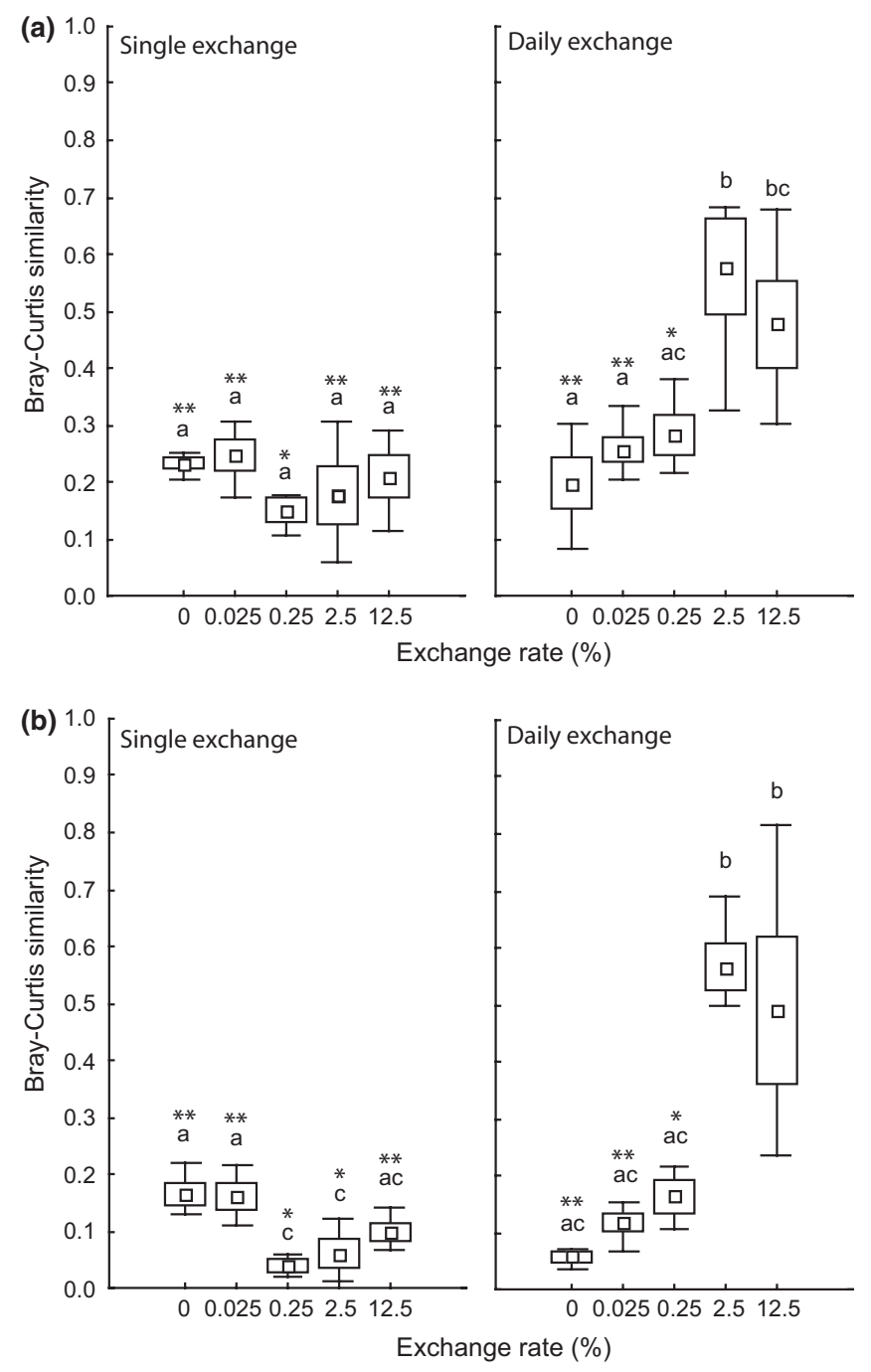

Fig. 2 Box plots of Bray-Curtis similarities in community composition, calculated between the mutually exchanged units for the different exchange rates, based on: (a) presence-absence data and (b) relative abundance data. Asterisks indicate significant differences in community composition between water from the two ponds within a given dispersal rate based on perMANOVAs $(* * P<0.01$; $* P<0.05)$. Different letter codes above the box plots designate significantly different Bray-Curtis similarity among dispersal rates based on one-way ANOVAs and Tukey HSD post hoc tests $(P<0.05)$. Boxes represent \pm standard error, and whiskers represent minimal and maximal values. $N=4$ or 5 . end of the experimental period [RDA: $P<0.05$ (PA) and $P<0.05$ (RA); perMANOVA: $P<0.05$ (PA) and $P<0.05$ (RA)]; even under the highest exchange rate, we could achieve with our centrifugation-based method [12.5\% exchange: RDA: $P=0.007$ (PA) and $P=0.011$ (RA); perMANOVA: $P=0.0075(\mathrm{PA})$ and $P=0.0079(\mathrm{RA})]$, showing that species sorting was effective after a single, large exchange. Also, the unexchanged control communities differed significantly between ponds [RDA: $P=0.016$ (PA) and $P=0.006$ (RA); perMANOVA: $P=0.0079$ (PA) and $P=0.0075$ (RA)], indicating that the two media still resulted in significantly divergent communities after the 20-day experimental period.

\section{Daily exchange: community structure}

There was a significant main effect of daily exchange rate on the composition of the bacterioplankton in our experimental units [RDA: $P=0.005$ (PA) and $P=0.0022$ (RA); perMANOVA: $P=0.0003$ (PA) and $P=0.0004$ (RA)]. PCA (Fig. 3) and NMDS (Fig. 4) plots visualise how an increasing rate of daily mutual exchange between the two communities led to convergence in their bacterial composition. Bray-Curtis similarities in community composition calculated among the reciprocally exchanged units became higher with increasing daily exchange rates (Fig. 2a,b, right panels), resulting in a significant positive correlation between the Bray-Curtis similarities of the mutually exchanged communities and the exchange rate, for both presence-absence (Spearman's rank: $r=0.753129 ; P<0.05$ ) and relative abundance data (Spearman's rank: $r=0.884943 ; P<0.05$ ). Bray-Curtis similarities in community composition calculated among the reciprocally exchanged units were higher, compared with those calculated for the unexchanged controls, at daily exchange rates of $2.5 \%$ [Tukey HSD: $P=0.001984$ (PA); $P=0.000339$ (RA)] and $12.5 \%$ [Tukey HSD: $P=0.022815$ (PA); $P=0.001293$ (RA)]. The communities in the two pond media differed significantly from each other under no exchange [perMANOVA: $P=0.0069$ (PA); $P=0.0082$ (RA) $]$ and at exchange rates of $0.025 \%$ [perMANOVA: $P=0.009$ (PA); $P=0.0076(\mathrm{RA})$ ] and $0.25 \%$ [perMANOVA: $P=0.0239$ (PA); $P=0.0274$ (RA)], but not at exchange rates of 2.5 or $12.5 \%$.

Additionally, there was a significant interaction effect between daily exchange rate and origin of the water [RDA: $P=0.001$ (PA and RA); perMANOVA: $P=0.0033$ (PA) and $P=0.0002$ (RA)]. The impact of daily exchange on community composition was different for the two ponds with divergence between exchanged communities 

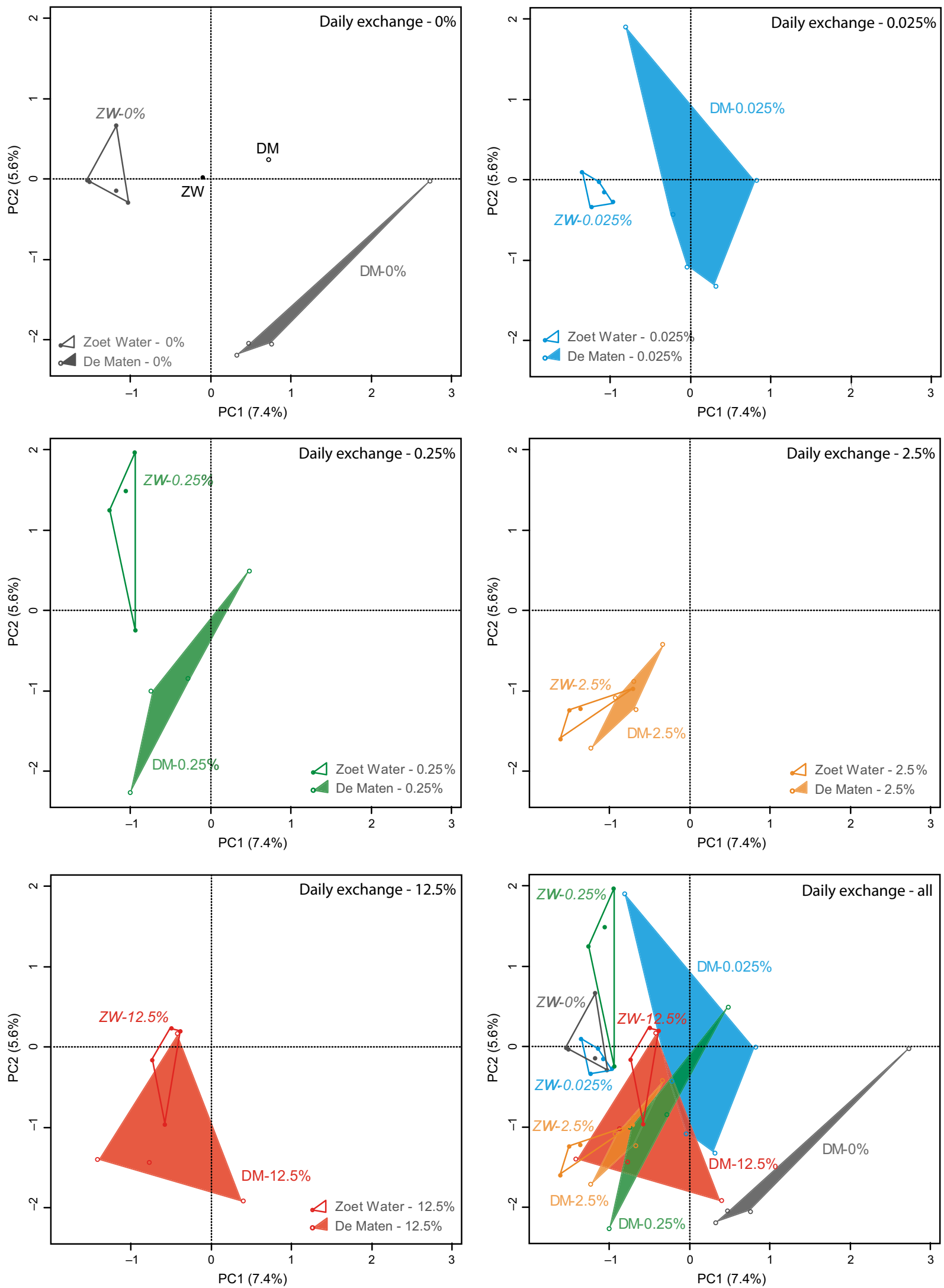

Fig. 3 PCA plots of the variation in bacterial community composition (relative abundance data) at different daily mutual exchange rates (daily exchange of $0,0.025,0.25,2.5$ and $12.5 \%$ of the cells present) plotted per exchange rate. DM $=$ De Maten; ZW $=$ Zoet Water. 


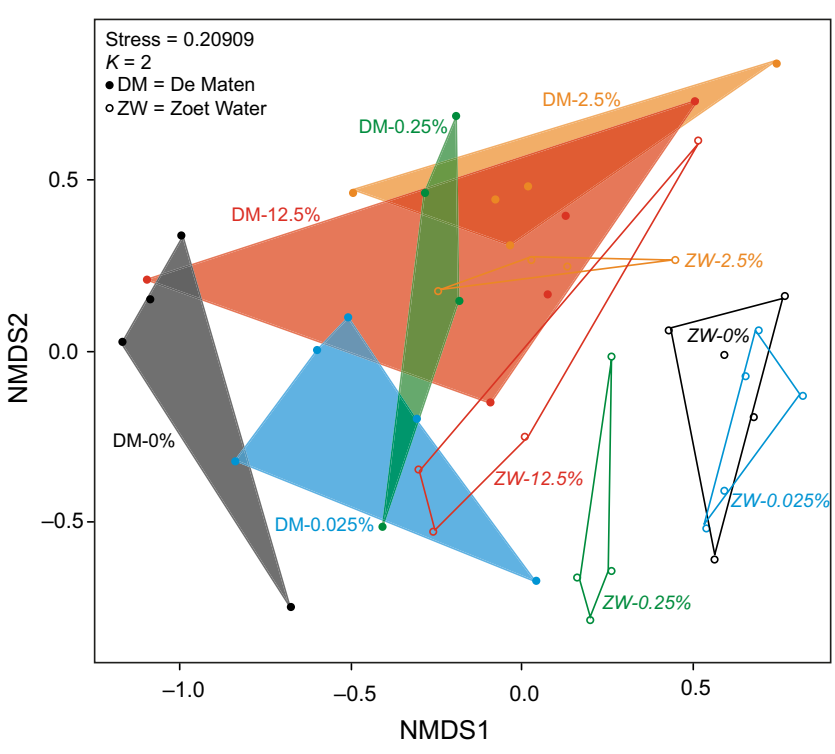

Fig. 4 NMDS plot of the variation in bacterial community composition (relative abundance data) at different daily mutual exchange rates (daily exchange of $0,0.025,0.25,2.5$ and $12.5 \%$ of the cells present). $\mathrm{DM}=$ De Maten; $\mathrm{ZW}=$ Zoet Water.

in Zoet Water from the control community of Zoet Water occurring at a lower dispersal rate $(0.25 \%)$ than divergence between exchanged and controlled communities of De Maten (2.5\%) (Table 2). The pattern generated by the data of Zoet Water (increasing significance with increasing exchange rate) was less erratic than that generated by De Maten, reflecting the higher variation among replicate samples in the De Maten samples.

\section{Daily exchange: ecosystem processes}

The Biolog GN2 microplate OD responses were significantly affected by pond of origin (RDA: $P=0.001$; perMANOVA: $P=0.0004$ ) and dispersal rate (RDA: $P=0.019$; perMANOVA: $P=0.0006$ ), and there was a significant interaction effect between pond of origin and dispersal rate
(RDA: $P=0.001$; perMANOVA: $P=0.0001$; see PCA plot, Fig. 5). The two non-exchanged communities were already fairly similar in terms of ecosystem processes (Fig. 6a). With increasing daily exchange, the Bray-Curtis similarity in ecosystem processes between the reciprocally exchanged units increased (Fig. 6a) (one-way ANOVA: $P=0.00004$ ), and a significant increase in similarity in terms of processes, compared with the non-exchanged treatments, was detected at an exchange ratio of $0.25 \%$ (Tukey HSD: $P=0.0028), 2.5 \%$ (Tukey HSD: $P=0.00067$ ) and $12.5 \%$ (Tukey HSD: $P=0.0002$ ) (Fig. 6a).

The significant increase in process similarity between mutually exchanged units with increasing dispersal rate was the result of a shift in the Zoet Water community, while the process properties of the De Maten communities remained relatively constant with exchange rate. This is reflected in a significant interaction effect between dispersal rate and pond of origin (see above), the pattern revealed by PCA (Fig. 5) and by the opposite patterns in Bray-Curtis similarities of Zoet Water and De Maten treatments calculated against the non-exchanged controls (Fig. 6b,c). Moreover, dispersal rate had a highly significant effect on the process properties of the Zoet Water community (RDA: $P=0.002$; perMANOVA: $P=0.0004$ ) (Fig. 5), while its effect on the De Maten processes was weak (RDA: $P=0.086$; perMANOVA: $P=0.0316$ ). However, when comparing the process characteristics of the exchanged communities with the non-exchanged community within water from a single pond, there was no significant divergence from the non-exchanged communities in none of the water types (RDA and perMANOVA: $P>0.05)$.

\section{Discussion}

Our results confirm earlier findings that species sorting is a powerful process in the freshwater bacterioplankton
Table 2 Summary of the $P$-values of perMANOVA and RDA pairwise analyses of T-RFLP data of the daily exchange experiment comparing each exchange treatment with the unexchanged control within water type to assess whether the exchange treatments resulted in significant divergence from the no-exchange control community

\begin{tabular}{|c|c|c|c|c|}
\hline \multirow[b]{2}{*}{ Comparison } & \multicolumn{2}{|c|}{$P$-value perMANOVA } & \multicolumn{2}{|c|}{$P$-value RDA } \\
\hline & $\begin{array}{l}\text { Presence- } \\
\text { absence }\end{array}$ & $\begin{array}{l}\text { Relative } \\
\text { abundances }\end{array}$ & $\begin{array}{l}\text { Presence- } \\
\text { absence }\end{array}$ & $\begin{array}{l}\text { Relative } \\
\text { abundances }\end{array}$ \\
\hline DM0\%-DM0.025\% & 0.1532 & 0.06099 & 0.184 & 0.081 \\
\hline DM0\%-DM0.25\% & 0.1414 & 0.05929 & 0.165 & 0.1 \\
\hline DM0\%-DM2.5\% & $0.008299^{* *}$ & $0.008499^{* *}$ & $0.012^{*}$ & $0.015^{*}$ \\
\hline DM0\%-DM12.5\% & 0.09969 & 0.09339 & 0.077 & 0.132 \\
\hline ZW0\%-ZW0.025\% & 0.4805 & 0.6525 & 0.428 & 0.656 \\
\hline ZW0\%-ZW0.25\% & $0.0174^{*}$ & $0.0233^{*}$ & $0.013^{*}$ & $0.01^{* *}$ \\
\hline ZW0\%-ZW2.5\% & $0.0217^{*}$ & $0.0241^{*}$ & $0.015^{*}$ & $0.025^{*}$ \\
\hline ZW0\%-ZW12.5\% & $0.007399^{* *}$ & $0.006399 * *$ & $0.013^{*}$ & $0.006^{* *}$ \\
\hline
\end{tabular}

$* P<0.05$.

$* * P<0.01$. 


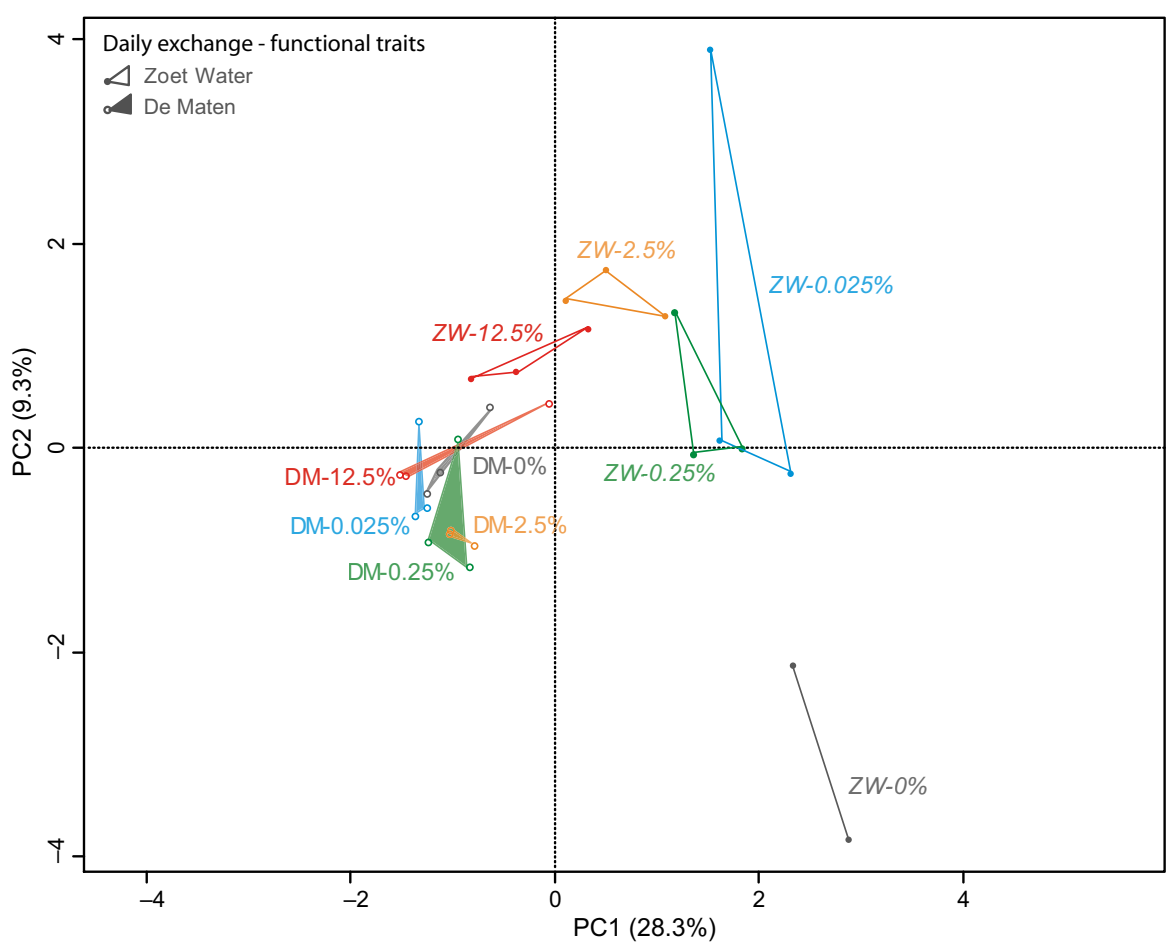

Fig. 5 PCA plot visualising the variation in Biolog GN2 metabolic response profiles over the different daily mutual exchange rates (daily exchange of 0.025 , $0.25,2.5$ and $12.5 \%$ of the cells present). $\mathrm{DM}=$ De Maten; $\mathrm{ZW}=$ Zoet Water.
(Van Der Gucht et al., 2007), but mass effects can overpower species sorting at high recurrent immigration (Lindström \& Östman, 2011). Moreover, we observed that the responses to mass effects were different at the level of community structure and ecosystem processes.

In the present study, we assessed the influence of a single, as well as a repeated (daily), exchange of bacteria on community composition and ecosystem processes. The single exchange was performed to test for dispersal limitation and neutral dynamics and to show whether the differences in media of the two ponds still resulted in two divergent communities over a time period of 20 days. The daily exchange experiment was performed to find at which exchange levels mass effects would be detectable. The cumulative number of cells exchanged over the 20-day time period was much higher in the daily exchange than in the single exchange experiment. In the treatment with a single initial exchange event, the exchanged communities did not converge over time and remained significantly dissimilar. Even at the highest rate of exchange that we could achieve in a single event (12.5\%), the communities inhabiting water from the two ponds remained different after 20 days, presumably due to environmental sorting caused by the differences in the water taken from the two ponds. This suggests that the medium exerted an influence on these bacterial communities, adding to the evidence of efficient species sorting in a variety of freshwater microbial communities (Van Der
Gucht et al., 2007; Bell, 2010; Drakare \& Liess, 2010; Logue \& Lindström, 2010; De Bie et al., 2012; Langenheder et al., 2012; Logue et al., 2012). The lack of an increase in similarity between exchanged communities with increasing dispersal in the single exchange experiment also shows that, under the experimental conditions, community structure was not driven by neutral dynamics and that dispersal limitation was not important in determining the observed dissimilarity in taxonomic composition. Under neutral dynamics, our experimental communities with a single exchange event would have converged increasingly with increasing dispersal, because communities are hypothesised to be structured by the relative colonisation of taxa, without any environmental sorting. Under dispersal limitation, we would expect that communities would converge even at low dispersal rates with a single exchange event and that similarity of the two communities would then increase no further with higher rates of dispersal (at least for presence-absence data).

From a methodological point of view, the results of the single exchange experiment also show that the communities present in the two media that were used were still very different after 20 days. This is important for the interpretation of our results, including those of the experiment with daily exchanges. While these latter tested for mass effects, our experiment with a single exchange was intended to test for the effects of dispersal limitation and neutral dynamics and to account for 

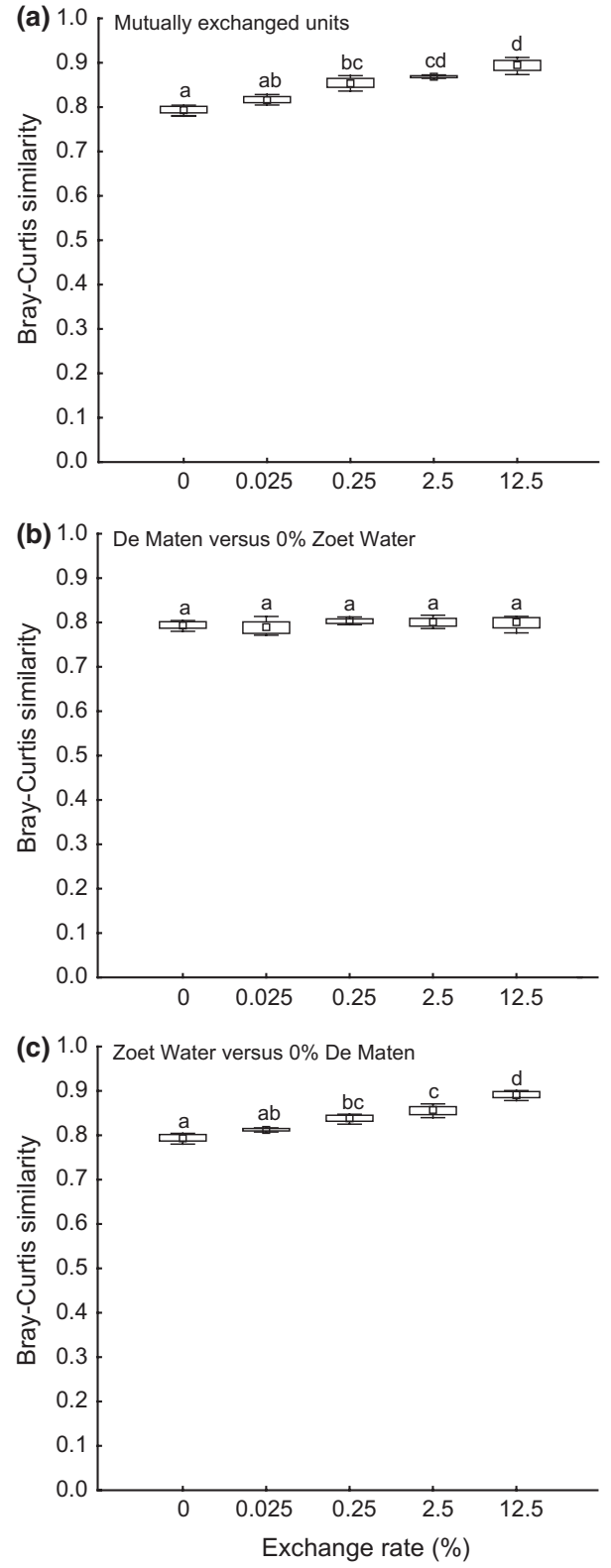

Fig. 6 Box plots of Bray-Curtis similarity in Biolog GN2 metabolic response profiles calculated: (a) between the daily mutually exchanged units for the different dispersal rates, (b) between the metabolic profiles of De Maten communities and the control of Zoet water for the different dispersal rates and (c) between the metabolic profiles of Zoet Water communities and the control of De Maten for the different dispersal rates. Different letter codes above the box plots designate significantly different Bray-Curtis similarities among dispersal rate treatments based on one-way ANOVAs and Tukey HSD post hoc tests $(P<0.05)$. Boxes represent \pm standard error, and whiskers represent minimal and maximal values. $N=3$.

methodological issues, including the effect of centrifugation on differential survival and pelletising of cells, the presence and exchange of predators and bacteriophages, and the exchange of centrifuged organic particles that could have changed the medium. In both cases, we started with communities isolated from nature and with natural media in order to mimic responses of reasonably complex natural communities to fairly complex media. Obviously, our experiments do not mimic natural conditions entirely, and the quality of the medium is expected to change during the course of the experiment. The bacterial communities in the control treatment without exchange had diverged somewhat from the original state after 20 days, and this may reflect drift or responses to changes in the medium, or the effect of predation and/ or centrifugation of cells. However, the control communities in the two different media showed no convergence in composition.

Moreover, with increasing cell exchange in a single event, there was no significant convergence of the exchanged communities in water from the two ponds. This is crucial in interpreting the pattern in the daily exchange experiment and indicates that methodological issues, including the transfer of predators and bacteriophages to non-adapted communities, the potential change in the medium due to transfer of organic particles and the potential negative effects of centrifugation, did not result in community convergence, which would have confounded observed mass effects. As exchange rate increased, the community composition in the Zoet Water medium did not change much compared with the unexchanged control, whereas the community in the De Maten medium did change with increasing exchange rate (Fig. 1). This may reflect some facilitation of the response to the change in quality of the De Maten medium caused by dispersal from the Zoet Water community (Shurin, 2001; Verreydt et al., 2012).

Daily cell exchange resulted in convergence in composition of the bacterioplankton in the two media and a significantly positive correlation between immigration rate and community similarity among daily exchanged communities. Given that this convergence in the bacterioplankton occurred while the media were kept separate, this indicates that mass effects are involved and that this is not the result of a convergence in medium characteristics. Overall, we observed a greater similarity in community composition of reciprocally exchanged communities compared with that of the unexchanged controls and no significant differences in the bacterioplankton among these reciprocally exchanged communities, at a daily exchange rate of $2.5 \%$ of cells or higher. Overall, we can thus conclude that species sorting between the two media was slowed down or inhibited by mass effects at these substantial rates of daily exchange. This value (2.5\% of cells day $\left.{ }^{-1}\right)$ confirms that relatively rapid 
dispersal is needed to create mass effects (Jones \& McMahon, 2009; Logue \& Lindström, 2010; Lindström \& Östman, 2011), but is lower than the estimate from the experimental results of Lindström \& Östman (2011), who observed that the largest changes in bacterial communities occurred when between $10 \%$ and $43 \%$ of the standing stock was transferred per day in their system. It seems thus that, at the community composition level, a daily influx of a considerable fraction of the standing stock ( $2.5 \%$ in our study) is necessary to overpower species sorting in freshwater heterotrophic planktonic bacteria, but that this value may vary with environmental conditions.

From a methodological point of view, it is striking that the community compositions in the treatments with high daily exchange converge to a different community composition from being intermediate to the two original, non-exchanged communities, as would be expected under a neutral model when mixing two communities. At first sight, this is not logical, given that we took care to keep the media different through centrifugation of the bacterial communities. It is possible, however, that the presence of taxa from the other habitat induced changes in the medium through differential transformation of organic compounds. These differences could accumulate during the experiment and gradually change the medium. Further, the introduction of bacteriophages and predators to non-adapted communities could have resulted in changes in the community composition. However, this does not frustrate the interpretation of our results in the light of dispersal limitation, species sorting and mass effects, given that our interpretation is based on the differential responses between the single or daily exchange compared with their respective controls.

In order to keep the two media separate while manipulating dispersal rates among them, we needed a method to isolate the bacteria from their medium and manipulate them independently. We used centrifugation, fully acknowledging that different taxa may be differentially sensitive to centrifugation. Any method, either centrifugation or filtration, has the potential to impose differential mortality on the bacteria. This does not interfere with our results, however, as centrifugation was applied equally across all treatments. We always centrifuged $50 \%$ of the medium, irrespective of the exact treatment. Our experiments evidently do not mimic natural conditions perfectly. Rather, the aim was to analyse patterns of dispersal limitation, species sorting and mass effects in complex bacterial communities. The percentages of effectively exchanged cells $(0.025,0.25,2.5,12.5 \%$ on a single or daily basis) were calculated based on a methodological test on the amount of cells that were pelletised by our centrifugation procedure, using communities of De Maten and Zoet Water, showing that $25 \%$ of the cells present in the centrifuged water volume were pelletised. While repeatability of this test was very high, and similar values were obtained for communities from both habitats, the procedure clearly results in some uncertainty. Our extrapolations therefore need to be interpreted with some caution. We chose centrifugation as a relatively noninvasive method for separating bacteria from their medium, but this comes at the cost of increased uncertainty.

Also, at the ecosystem process level, measured as the Biolog GN2 metabolic potential of the community, a significant effect of dispersal rate was detected with daily cell exchange. However, while the bacterial community was significantly affected by dispersal at an immigration rate of $2.5 \%$, our ecosystem process measures were affected at dispersal rates of $0.25 \%$. That community structure and ecosystem processes may respond differently to disturbance has been suggested and observed before (Allison \& Martiny, 2008; Comte \& Del Giorgio, 2010; Lindström \& Östman, 2011; Berga, Szekely \& Langenheder, 2012). Like Berga et al. (2012), we observed that ecosystem processes responded faster than community structure, which suggests that presenceabsence of specific, non-abundant taxa can make a difference in terms of the functional profile of communities. It may also reflect the low resolution of the fingerprint technique T-RFLP, potentially missing small changes in relative abundance or failing to detect rare taxa.

Starting with complex natural bacterioplankton grown in isolation or with increasing dispersal from another community, we observed mass effects in treatments with substantial dispersal (exchange of $2.5 \%$ of cells daily). While mass effects are thus a plausible structuring mechanism for metacommunities, they are unlikely to occur in systems that are not hydrologically connected, where exchange rates are low. However, note that dispersal rates resulting in mass effects differed at the ecosystem process and community composition levels and also differed between the two source ponds. The reasons for these variations are still unclear, and further research should focus on the underlying mechanisms shaping metacommunity structure under variable conditions in nature.

\section{Acknowledgments}

The authors thank three anonymous referees for their constructive remarks and Prof A. Hildrew for extensive editing that strongly improved our manuscript. This 
study was financially supported by FWO-Vlaanderen (Fund for Scientific Research - Flanders, Belgium) research project G.0978.10N and by the KU Leuven Research Fund Centre of Excellence PF.2010.07. BP and KR enjoyed PhD fellowships by the Institute for Science and Technology - Flanders, Belgium.

\section{References}

Allison S.D. \& Martiny J.B.H. (2008) Resistance, resilience, and redundancy in microbial communities. Proceedings of the National Academy of Sciences of the United States of America, 105, 11512-11519.

Beisner B.E., Peres Neto P.R., Lindstrom E.S., Barnett A. \& Longhi M.L. (2006) The role of environmental and spatial processes in structuring lake communities from bacteria to fish. Ecology, 87, 2985-2991.

Bell T. (2010) Experimental tests of the bacterial distancedecay relationship. The ISME Journal, 4, 1357-1365.

Berga M., Szekely A.J. \& Langenheder S. (2012) Effects of disturbance intensity and frequency on bacterial community composition and function. PLoS ONE, 7, e36959.

Chase J.M. \& Leibold M.A. (2002) Spatial scale dictates the productivity-biodiversity relationship. Nature, 416, 427430.

Codeço C.T. \& Grover J.P. (2001) Competition along a spatial gradient of resource supply: a microbial experimental model. American Naturalist, 157, 300-315.

Comte J. \& Del Giorgio P.A. (2010) Linking the patterns of change in composition and function in bacterioplankton successions along environmental gradients. Ecology, 91, 1466-1476.

Crump B.C., Adams H.E., Hobbie J.E. \& Kling G.W. (2007) Biogeography of bacterioplankton in lakes and streams of an arctic tundra catchment. Ecology, 88, 1365-1378.

Crump B.C., Kling G.W., Bahr M. \& Hobbie J.E. (2003) Bacterioplankton community shifts in an arctic lake correlate with seasonal changes in organic matter source. Applied and Environmental Microbiology, 69, 2253-2268.

Danielson B.J. (1991) Communities in a landscape - The influence of habitat heterogeneity on the interactions between species. American Naturalist, 138, 1105-1120.

Danovaro R., Luna G.M., Dell'anno A. \& Pietrangeli B. (2006) Comparison of two fingerprinting techniques, terminal restriction fragment length polymorphism and automated ribosomal intergenic spacer analysis, for determination of bacterial diversity in aquatic environments. Applied and Environmental Microbiology, 72, 5982-5989.

De Bie T., De Meester L., Brendonck L., Martens K., Goddeeris B., Ercken D. et al. (2012) Body size and dispersal mode as key traits determining metacommunity structure of aquatic organisms. Ecology Letters, 15, 740-747.

Drakare S. \& Liess A. (2010) Local factors control the community composition of cyanobacteria in lakes while heterotrophic bacteria follow a neutral model. Freshwater Biology, 55, 2447-2457.

Dunbar J., Ticknor L.O. \& Kuske C.R. (2001) Phylogenetic specificity and reproducibility and new method for analysis of terminal restriction fragment profiles of $16 \mathrm{~S}$ rRNA genes from bacterial communities. Applied and Environmental Microbiology, 67, 190-197.

Forbes A.E. \& Chase J.N. (2002) The role of habitat connectivity and landscape geometry in experimental zooplankton metacommunities. Oikos, 96, 433-440.

Garland J.L. \& Mills A.L. (1991) Classification and characterisation of heterotrophic microbial communities on the basis of patterns of community-level sole-carbon-source utilisation. Applied and Environmental Microbiology, 57, 2351-2359.

Gonzalez A. \& Chaneton E.J. (2002) Heterotroph species extinction, abundance and biomass dynamics in an experimentally fragmented microecosystem. Journal of Animal Ecology, 71, 594-602.

Hanson C.A., Fuhrman J.A., Horner-Devine M.C. \& Martiny J.B.H. (2012) Beyond biogeographic patterns: processes shaping the microbial landscape. Nature Reviews Microbiology, 10, 497-506.

Hartmann M., Frey B., Kolliker R. \& Widmer F. (2005) Semi-automated genetic analyses of soil microbial communities: comparison of T-RFLP and RISA based on descriptive and discriminative statistical approaches. Journal of Microbiological Methods, 61, 349-360.

Holt R.D. (1985a) Density-dependent mortality, non-linear competitive interactions, and species coexistence. Journal of Theoretical Biology, 116, 479-493.

Holt R.D. (1985b) Population dynamics in two-patch environments: some anomalous consequences of an optimal habitat distribution. Theoretical Population Biology, 28, 181208.

Holt R.D., Barfield M. \& Gonzalez A. (2003) Impacts of environmental variability in open populations and communities: 'inflation' in sink environments. Theoretical Population Biology, 64, 315-330.

Holt R.D. \& Loreau M.(2001) Biodiversity and ecosystem functioning: the role of trophic interactions and the importance of system openness. In: Monographs in Population Biology. The Functional Consequences of Biodiversity: Empirical Progress and Theoretical Extensions (Eds A.P. Kinzig , S.W. Pacala \& D. Tilman ), pp. 246-262. Princeton University Press, Princeton.

Holyoak M. (2000) Habitat patch arrangement and metapopulation persistence of predators and prey. American Naturalist, 156, 378-389.

Holyoak M., Leibold M.A. \& Holt R.D. (2005) Metacommunities: Spatial Dynamics and Ecological Communities. pp. 520. University of Chicago Press, Chicago.

Hubbell S.P. (2006) Neutral theory and the evolution of ecological equivalence. Ecology, 87, 1387-1398.

Jones S.E. \& McMahon K.D. (2009) Species-sorting may explain an apparent minimal effect of immigration on 
freshwater bacterial community dynamics. Environmental Microbiology, 11, 905-913.

Kneitel J.M. \& Miller T.E. (2003) Dispersal rates affect species composition in metacommunities of Sarracenia purpurea inquilines. American Naturalist, 162, 165-171.

Langenheder S., Berga M., Östman Ö. \& Székely A.J. (2012) Temporal variation of beta-diversity and assembly mechanisms in a bacterial metacommunity. The ISME Journal, 6, 1107-1114.

Langenheder S. \& Székely A.J. (2011) Species sorting and neutral processes are both important during the initial assembly of bacterial communities. The ISME Journal, 5, 1086-1094.

Leibold M.A. (1998) Similarity and local co-existence of species in regional biotas. Evolutionary Ecology, 12, 95-110.

Leibold M.A., Holyoak M., Mouquet N., Amarasekare P., Chase J.M., Hoopes M.F. et al. (2004) The metacommunity concept: a framework for multi-scale community ecology. Ecology Letters, 7, 601-613.

Levin S.A. (1974) Dispersion and population interactions. American Naturalist, 108, 207-228.

Lindström E.S. \& Bergström A.K. (2004) Influence of inlet bacteria on bacterioplankton assemblage composition in lakes of different hydraulic retention time. Limnology and Oceanography, 49, 125-136.

Lindström E.S., Feng X.M., Graneli W. \& Kritzberg E.S. (2010) The interplay between bacterial community composition and the environment determining function of inland water bacteria. Limnology and Oceanography, 55, 2052-2060.

Lindström E.S., Forslund M., Algesten G. \& Bergström A.K. (2006) External control of bacterial community structure in lakes. Limnology and Oceanography, 51, 339-342.

Lindström E.S. \& Langenheder S. (2012) Local and regional factors influencing bacterial community assembly. Environmental Microbiology Reports, 4, 1-9.

Lindström E.S. \& Östman Ö. (2011) The importance of dispersal for bacterial community composition and functioning. PLoS ONE, 6, e25883.

Liu W.T., Marsh T.L., Cheng H. \& Forney L.J. (1997) Characterization of microbial diversity by determining terminal restriction fragment length polymorphism of genes encoding 16S rRNA. Applied and Environmental Microbiology, 63, 4516-4522.

Logue J.B., Langenheder S., Andersson A.F., Bertilsson S., Drakare S., Lanzen A. et al. (2012) Freshwater bacterioplankton richness in oligotrophic lakes depends on nutrient availability rather than on species-area relationships. The ISME Journal, 6, 1127-1136.

Logue J.B. \& Lindström E.S. (2010) Species sorting affects bacterioplankton community composition as determined by $16 \mathrm{~S}$ rDNA and $16 \mathrm{~S}$ rRNA fingerprints. The ISME Journal, 4, 729-738.

Masin M., Jezbera J., Nedoma J., Straskrabova V., Hejzlar J. \& Simek K. (2003) Changes in bacterial community composition and microbial activities along the longitudinal axis of two canyon-shaped reservoirs with different inflow loading. Hydrobiologia, 504, 99-113.

Matthiessen B. \& Hillebrand H. (2006) Dispersal frequency affects local biomass production by controlling local diversity. Ecology Letters, 9, 652-662.

Mouquet N. \& Loreau M. (2002) Coexistence in metacommunities: the regional similarity hypothesis. American Naturalist, 159, 420-426.

Mouquet N. \& Loreau M. (2003) Community patterns in source-sink metacommunities. American Naturalist, 162, 544-557.

Nelson C.E., Sadro S. \& Melack J.M. (2009) Contrasting the influences of stream inputs and landscape position on bacterioplankton community structure and dissolved organic matter composition in high-elevation lake chains. Limnology and Oceanography, 54, 1292-1305.

Ofiteru I.D., Lunn M., Curtis T.P., Wells G.F., Criddle C.S., Francis C.A. et al. (2010) Combined niche and neutral effects in a microbial wastewater treatment community. Proceedings of the National Academy of Sciences of the United States of America, 107, 15345-15350.

Oksanen J., Blanchet F., Kindt R., Legendre P., Minchin P., O'hara R. et al. (2013) vegan: Community Ecology Package. R-package version 2.0-7. Available at: http:/ CRAN. R-project.org/package=vegan.

Östman Ö., Drakare S., Kritzberg E.S., Langenheder S., Logue J.B. \& Lindström E.S. (2010) Regional invariance among microbial communities. Ecology Letters, 13, 118-127.

Östman Ö., Drakare S., Kritzberg E.S., Langenheder S., Logue J.B. \& Lindström E.S. (2012) Importance of space and the local environment for linking local and regional abundances of microbes. Aquatic Microbial Ecology, 67, 35-U158.

Preston-Mafham J., Boddy L. \& Randerson P.F. (2002) Analysis of microbial community functional diversity using sole-carbon-source utilisation profiles - a critique. FEMS Microbiology Ecology, 42, 1-14.

Pulliam H.R. (1988) Sources, sinks, and population regulation. American Naturalist, 132, 652-661.

Pulliam H.R. (2000) On the relationship between niche and distribution. Ecology Letters, 3, 349-361.

Schauer R., Bienhold C., Ramette A. \& Harder J. (2010) Bacterial diversity and biogeography in deep-sea surface sediments of the South Atlantic Ocean. The ISME Journal, 4, 159-170.

Shabarova T., Widmer F. \& Pernthaler J. (2013) Mass effects meet species sorting: transformations of microbial assemblages in epiphreatic subsurface karst water pools. Environmental Microbiology, 15, 2476-2488.

Shmida A. \& Ellner S. (1984) Coexistence of plant-species with similar niches. Vegetatio, 58, 29-55.

Shmida A. \& Whittaker R.H. (1981) Pattern and biological microsite effects in 2 shrub communities, Southern-California. Ecology, 62, 234-251.

Shmida A. \& Wilson M.V. (1985) Biological determinants of species diversity. Journal of Biogeography, 12, 1-20. 
Shurin J.B. (2001) Interactive effects of predation and dispersal on zooplankton communities. Ecology, 82, 3404-3416.

Sloan W.T., Lunn M., Woodcock S., Head I.M., Nee S. \& Curtis T.P. (2006) Quantifying the roles of immigration and chance in shaping prokaryote community structure. Environmental Microbiology, 8, 732-740.

Smalla K., Oros-Sichler M., Milling A., Heuer H., Baumgarte S., Becker R. et al. (2007) Bacterial diversity of soils assessed by DGGE, T-RFLP and SSCP fingerprints of PCR-amplified 16S rRNA gene fragments: do the different methods provide similar results? Journal of Microbiological Methods, 69, 470-479.

Van Der Gucht K., Cottenie K., Muylaert K., Vloemans N., Cousin S., Declerck S. et al. (2007) The power of species sorting: local factors drive bacterial community composition over a wide range of spatial scales. Proceedings of the National Academy of Sciences of the United States of America, 104, 20404-20409.

Venail P.A., Maclean R.C., Bouvier T., Brockhurst M.A., Hochberg M.E. \& Mouquet N. (2008) Diversity and productivity peak at intermediate dispersal rate in evolving metacommunities. Nature, 452, 210-U257.
Venail P.A., Maclean R.C., Meynard C.N. \& Mouquet N. (2010) Dispersal scales up the biodiversity-productivity relationship in an experimental source-sink metacommunity. Proceedings of the Royal Society B-Biological Sciences, 277, 2339-2345.

Verreydt D., De Meester L., Decaestecker E., Villena M.-J., Van Der Gucht K., Vannormelingen P. et al. (2012) Dispersal-mediated trophic interactions can generate apparent patterns of dispersal limitation in aquatic metacommunities. Ecology Letters, 15, 218-226.

Whitaker R.J., Grogan D.W. \& Taylor J.W. (2003) Geographic barriers isolate endemic populations of hyperthermophilic archaea. Science, 301, 976-978.

Wilson M.V. \& Shmida A. (1984) Measuring beta diversity with presence-absence data. Journal of Ecology, 72, 10551064.

Woodcock S., Van Der Gast C.J., Bell T., Lunn M., Curtis T.P., Head I.M. et al. (2007) Neutral assembly of bacterial communities. FEMS Microbiology Ecology, 62, 171-180.

(Manuscript accepted 9 June 2014) 